\title{
Effect of Boric Acid Solubility in Steam on the Process of Mass Transfer during Emergency Cooling of VVER-1200 Nuclear Reactor
}

\author{
Md. Rezouanul Kabir Hridoy ${ }^{1}$, Morozov A.V. ${ }^{2}$, Md Saif Kabir ${ }^{3}$ \\ Department of Nuclear Physics and Engineering, National Research Nuclear University (MEPhI), Russia
}

Emails: ${ }^{* 1}$ rezouanul@oiate.ru; ${ }^{2}$ morozovandrey.email@gmail.com ; ${ }^{3}$ mdsaifkabir@oiate.ru

\section{ARTICLE INFO}

\section{Article History:}

Received: 21st August 2021

Revised: $15^{\text {th }}$ November 2021

Accepted: $16^{\text {th }}$ November 2021

Published: 23rd Decemer 2021

\section{Keywords:}

VVER-1200

Crystallization

Hydroaccumulator-1, 2

Boric Acid

Reactor Core

\section{A B S T RAC T}

The mechanisms of boric acid mass transfer in a VVER-1200 reactor core are studied in this work in the event of a major circulatory pipeline rupture and loss of all AC power. The VVER-1200's passive core cooling technology is made up of two levels of hydro accumulators. They use boric acid solution with a concentration of $16 \mathrm{~g} \mathrm{H} 3 \mathrm{BO} 3 / \mathrm{kg} \mathrm{H} 20$ to control the reactivity. Because of the long duration of the accident process, the coolant with high boron content starts boiling and steam with low concentration of boric acid departs the core. So, conditions could arise in the reactor for possible accumulation and subsequent crystallization of boric acid, causing the core heat removal process to deteriorate. Calculations were carried out to estimate the likelihood of H3BO3 build-up and subsequent crystallization in the core of the VVER reactor. According to the calculations, during emergency the boric acid concentration in the reactor core is $0.153 \mathrm{~kg} / \mathrm{kg}$ and $0.158 \mathrm{~kg} / \mathrm{kg}$ in both the events of solubility of steam and without solubility of steam respectively and it does not exceed the solubility limit which is about $0.415 \mathrm{~kg} / \mathrm{kg}$ at water saturation temperature. No precipitation of boric acid occurs within this time during the whole emergency process. Therefore, findings of the study can be used to verify whether the process of decay heat removal is affected or not.

\section{INTRODUCTION}

The majority pressing issues that need to be addressed to the industry of nuclear power today are for ensuring the safety of new electricity plants with nuclear reactors. The passive safety system (PSS) functioning ensures reactor unit safety during loss of coolant accident (LOCA) in the water-water energetic reactor (VVER-1200) reactor project. PSS removes heat through the core by supplying solution of boric acid having concentration of $16 \mathrm{~g} / \mathrm{kg}$ to the reactor (Kalyakin et al., 2003; Morozov et al., 2009). Heat removal through fuel elements can deteriorate as a result of this and this can lead to a negative environmental effect. The review of potential incidents at nuclear power plant for an era of VVER fitted with passive protection systems would benefit greatly from the evaluation of boric acid removal from the core. Experiments have demonstrated that high amounts of boric acid can be achieved in the core simulator, resulting in its crystallization and disrupting coolant circulation. Droplet entrainment has also been found to cause the boric acid's concentration to rise in the core. In experiments which were carried out without a separator to prevent droplet entrainment, boric acid (H3BO3) concentration in the core simulator reached equilibrium below the saturation limit, and crystallization was not seen. This was due to the fact that steam took out the same amount of boric acid solution as vapour. Calculations and experiments revealed that the capturing of boric acid droplets was not as strong when pure water was used. This suggests that both $\mathrm{H}_{3} \mathrm{BO}_{3}$ and the presence of other impurities in water have a direct effect in the process of droplet entrainment. It necessitates theoretical and analytical research into the mechanism of boric acid droplet entrainment in the context of VVER in emergency boiling mode. The key goal of this study is to figure out how much boric acid droplets entrain during accident. The following issues must be resolved in order to accomplish this goal:

- Calculating and analysing of VVER reactor plant's mass transfer procedures (Morozov \& Remizov, 2012).

- Calculating and analyzing the flow rates of Hydroaccumulator $2^{\text {nd }}$ stage, PHRS and flow rates due to 
droplet entrainment in emergency process (Kalyakin et al., 2014)

\section{THEORITICAL BACKGROUND}

In emergency, there are two options for removing boric acid through the reactor core: In the steam-water mixture, through droplet entrainment and secondly, because of steam solvent ability.

\section{A. Processes of droplet entrainment}

In two-phase flow systems, understanding the conditions that contribute towards entrainment of a liquid film on the surface via a gas flow is crucial for mass and heat transfer operations. The onset of entrainment has a significant impact on the processes of mass, momentum and energy transmission (Ishii and Grolmes, 1975). In several methods, a gas flow can be entrained by a wavy liquid surface. The speed and distortion of wave crests are governed by hydrodynamic and surface forces. Under the horizontal air/water channel (HAWAC), Figure 1 demonstrates droplet production at wave crest in a slug flow situation (Vallée et al., 2008).

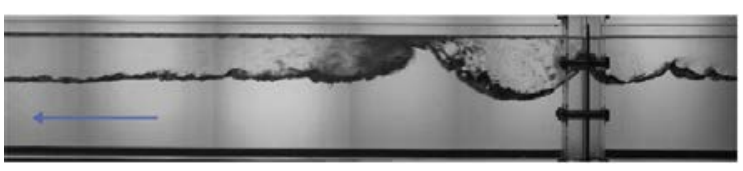

Figure 1: Droplets form at the peak of the wave (Vallée et al., 2008)

These pressures cause a severe distortion of the interface under certain conditions resulting in fragmentation of a section of a wave into numerous droplets. The surrounding flow pattern as well as the shape of the interface impact wave crests forces. Figure 2 depicts the four primary types of entrainment processes (Ishii \& Grolmes, 1975). The turbulent gas flow shears the tops of big amplitude roll waves, away through wave crests in first kind (Hewitt and Hall-Taylor, 1970). The drag coefficient operating on the wave tops changes shape of the interface against the sustaining strain of liquid surface tension. The 2nd sort of entrainment occurs when a gas flow undercuts the liquid film (Hewitt \& Hall-Taylor, 1970).

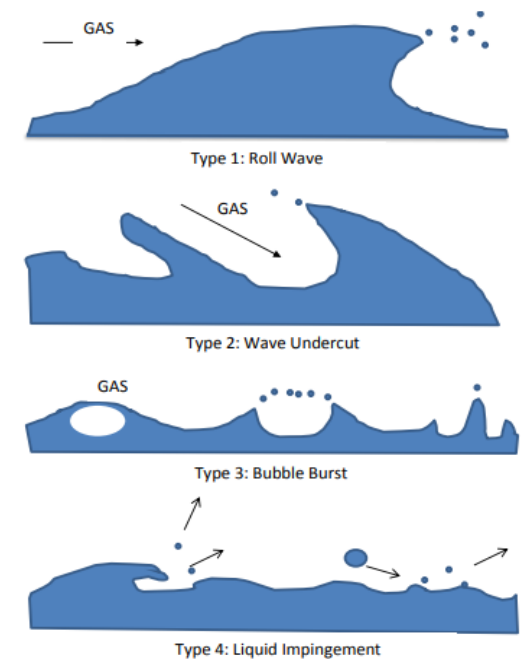

Figure 2: Different droplets entrainment mechanisms (Ishii \& Grolmes, 1975)
The third type is associated with gas bubbles exploding (Newitt et al., 1954). Liquid impingement droplets or bulk onto the film contact causes the fourth form of entrainment. This technique may create tiny droplets when roll-wave fronts advance. All of these scenarios should be covered by a universal droplet entrainment model.

\section{B. Solubility of Boric Acid in Steam}

In steam or supercritical water, all salts and oxides are relatively soluble. The degree of solubility is a complicated function of the substance's composition as well as the density and temperature of the water phase. At a constant temperature, solubility usually rises with density. The challenges caused by this solubility in the steam cycle are determined by cycle parameters and solute properties. However, deposits in the turbine typically extracted with steam from the steam generator chemicals, the most common of which are silica, $\mathrm{Na}-\mathrm{OH}, \mathrm{Na} 2 \mathrm{SO} 4$ and copper oxides caused problems in conventional energy technology. Figure 3 demonstrates the concentration of steam solid in comparison to steam pressure.

The problem was solved principally by lowering the incoming amounts of chemicals in the unit and in case of silica by lowering its volatility by regulating the boiler's water alkalinity at its ideal level. The removal of water vapour from the transfer of substances might cause problems; therefore, it must be done mechanically using a device that monitors steam separation and draining. Chemistry of feed-water and boiler water has a direct impact on steam purity. Even at its finest, steam created during the boiling process is never totally clean. Solids deposition and corrosion in super-heaters and turbines are prevalent issues. Good steam chemistry management is critical in industrial units that do not have turbines. The term "carryover" refers to the process of solids being converted to steam. The following factors impact carryover:

- Almost all solids are soluble in steam. Solids become more soluble as boiler pressure increases.

- Even with the best steam separating devices, moisture droplets still enter the steam.

- Sulphate and chloride will enter steam as ammoniated salts.

- Carryover is increased by inadequate drum level management, poor drum structure or high particles accumulation in drum water. Dissolved solids still have a direct access to the steam system even if the drum is working effectively and limiting carryover.

In the event of an emergency, boric acid mass transfer must be investigated so that the risk pertaining to boric acid accumulation in the VVER core can be assessed. Whenever the main circulation pipeline ruptures in large loss of coolant accident, the water tanks hydroaccumulator1 \& hydroaccumulator-2 are activated to provide boric acid to the core (Morozov \& Remizov, 2012a). In addition to boric acid, this accesses the reactor through water storage tanks and the activities of the passive heat removal system causing condensate to be dispersed into the core of the SGs 
of three secondary exposed circuits about 1.5 hours shortly after the accident (Morozov \& Remizov, 2012). In addition, there are two methods to address mass transfer of boric acid (Kalyakin et al., 2014). Because the flow of boric acid into the downstream portion by operation of second stage hydro accumulator in a quantity suitable for natural convection, the condensation is mixed with the boric acid accreted in the first scenario at the bottom part of the reactor. A little amount of boric acid is added to the flow (Morozov \& Remizov, 2012a).

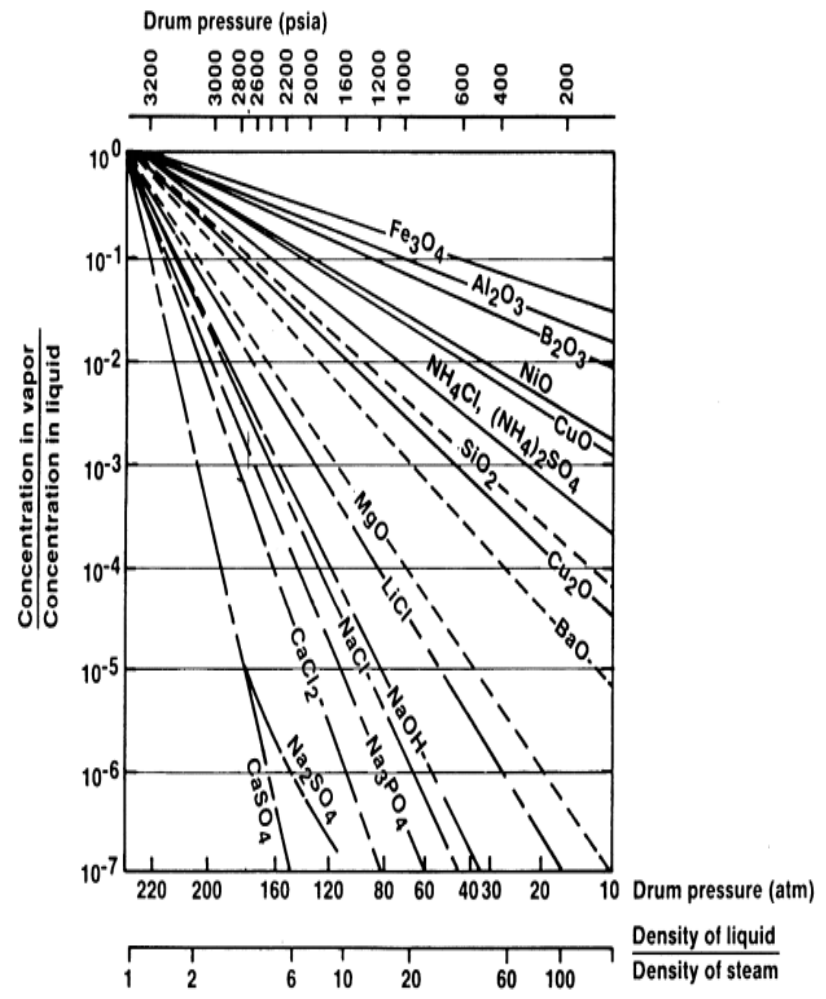

Figure 3: Concentration of Steam Solids vs. Steam Pressure

In the second scenario, condensate and HA-2-supplied boric acid do not combine. Then boric acid sinks towards the bottom region of the core as a result of increased density. Above this layer, condensate with a low acid content is collected. As a result, circumstances are produced for the concentration of boric acid to rise close to the lower part of the core for the acid to precipitate. Boric acid's density is determined by its concentration, as well as the density of water. Temperature affects the high concentrations in agreement with the commencement of the formation of crystals: an increase in temperature raises it dramatically, while a drop in temperature reduces it. Taking into account the creation of steam as a result of the coolant boiling in reactor, boric acid's concentration at the edge of the core should rise. Furthermore, the solubility in the reactor's volume might approach its maximum value.

The density of a boric acid solution is determined by the concentration of the acid and the density of the water (Schmal \& Ivanov, 2015). The temperature affects the maximum concentration of boric acid solution that corresponds to the start of crystallization (Cohen, 1973): Temperature increase cause a rapid rise in the maximum concentration of boric acid solution, whereas temperature decrease lead to a reduction (Figure 4).

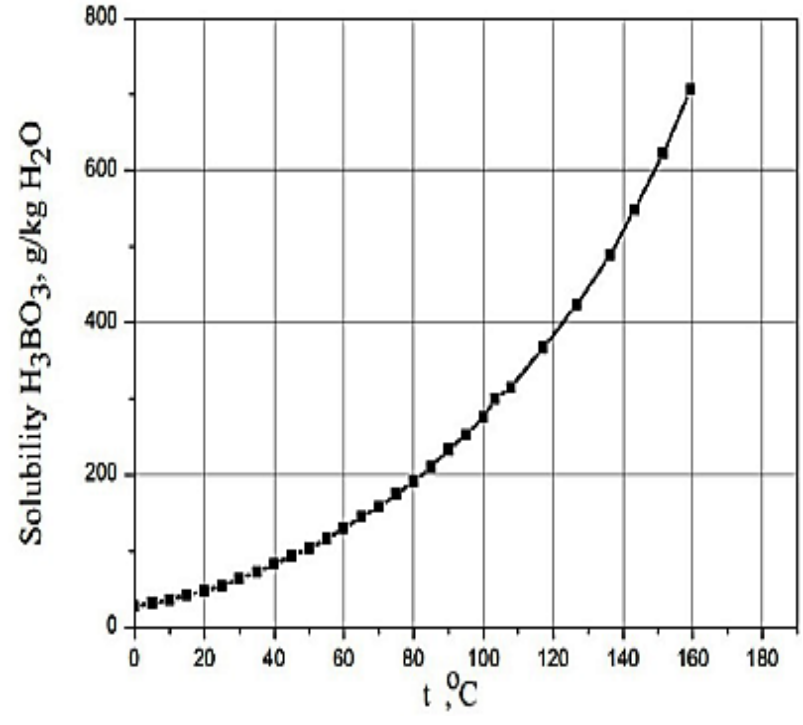

Figure 4: The diagram of the solubility of boric acid in water temperature (Cohen, 1973)

\section{METHODOLOGY}

A test facility was established at IPPE JSC (IPPE JSC is a research and development institute in the field of nuclear technology, located in Obninsk, Russia) to look into the mechanisms of boric acid mass transport. It is difficult to investigate these actual scenarios in nuclear power plant, so, this facility was used to obtain data.

\section{A. Experimental Procedure \\ i. Test Facilities}

The IPPE JSC test facility consists of a 14-liter solution preparation tank, an internal $27 \mathrm{~mm}$ stainless steel test section and a $2800 \mathrm{~mm}$ height, a steam condenser as well as a steam separator. The lower evaporative portion of the testing centre is heated by an adjustable heater. Insulated \& heated technologies lines having shut-off valves link the facility's major equipment to one another (Hassan et al., 2015). In the test section, the distance between the boiling water level and the steam extraction line in the VVER reactor and the low-level generator of the cold loop of the major circulatory pipeline corresponds to the height from the evaporative layer (Schmal \& Ivanov, 2015).

The METRAN-150 gauge is used for measurement, display and transfer to pressure parameter control systems. A glass level gauge is used to measure the quantity of boric acid mixture in the test section. The temperature is monitored using $\mathrm{K}$ type cable temperature sensors with a diameter of around $\mathrm{mm}$ (measurement inaccuracy of $1{ }^{\circ} \mathrm{C}$ ). The data collecting system's measurement channels have a $1 \mathrm{~Hz}$ sampling rate. The percentage of $\mathrm{H} 3 \mathrm{BO} 3$ in the condensate specimens produced through condensing the steam created throughout the test specimen using boiling boric acid solution, is an essential measurable parameter in the tests.

\section{ii. Experiment Steps}

At the commencement of the test, the solution processing tank is full with the proper quantities of distilled water as well as dry powder H3BO3 to create a boric acid solution with a predetermined concentration. The solution was then 
stirred using a mechanical device until the dry H3BO3 was completely dissolved which was observed through portholes in the tank. Nitrogen was subsequently transferred from gas cylinder to the solution preparation tank's top volume through the gas reducer. Temperature of the solution processing tank, the test section as well as the H3BO3 solution supply line was also elevated to the proper levels. Throughout the experiment, the required temperature should be maintained with a $1^{\circ} \mathrm{C}$ accuracy using a relay controller. After the preheating is completed, the valves in the $\mathrm{H} 3 \mathrm{BO} 3$ solution supply line are released in order and the bottom half of the test section is loaded to the desired level using a boric acid solution with a concentration equivalent to that in the preparation tank. Simultaneously, a blow-off valve is opened to blast the steam-air combination out of the primary components into the environment, preventing the existence of a steam and air combination in test area. Power of the steam condenser is then controlled. The air fans are turned on to increase the power of the system.

The consistency of the quantity in the test section's pressure as well as the temperature of condensate at the output of the condenser is a condition for achieving the necessary value of the condensation power. After that, a $50 \mathrm{ml}$ sample of condensate is transported to the measurement containers at regular intervals throughout the experiment. The duration of condensate collected at the moment of sampling was used to establish the facility's actual evaporation power (Hassan et al., 2015).

The calibration technique was accustomed to measure the boric acid's concentration in the samples after experiment was completed. Figure 5 depicts an organization of the test facility's primary equipment and Figure 6 depicts the facility's process flow chart.

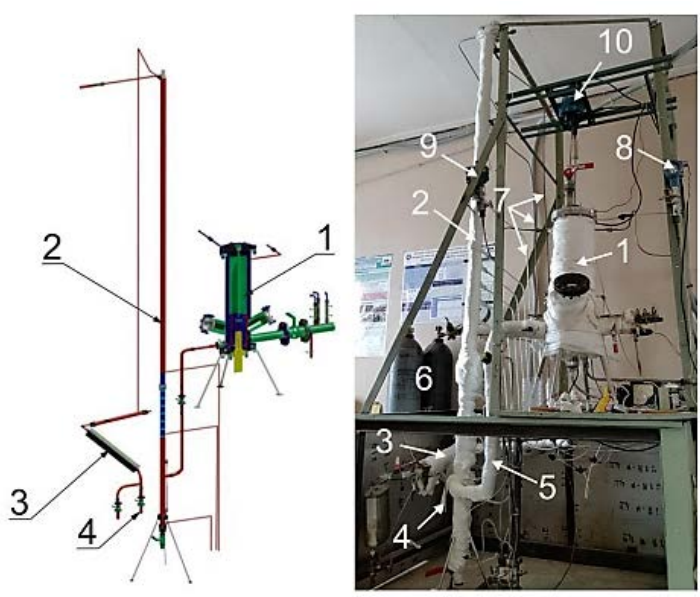

Figure 5: Arrangement of the test facility's major equipment (Hassan et al., 2015): 1) solution preparation tank; 2) test section (TS); 3) condenser; 4) sampling; 5) line of H3B03 solution supply; 6) a cylinder of the gas supply system; 7) steam extraction lines; 8, 9) pressure sensors; 10) mixing device

\section{iii. Initial Data and Assumption}

It is not feasible to compute droplet entrainment processes using dependencies in the early stages of an accident. As a result, the whole emergency procedure was separated into two sections throughout the computation analysis. Figure 7 (a) shows that the steam-water combination is splashed out in reactor volumes and contained in the pipeline in the early phase of an accident via the nuclear reactor core. The sprayed liquid water then rises over the hole of the reactor barrel, and then the steam-water mixture gets sprinkled from the core and goes into the reactor chamber. It finally goes to the containment since the pipeline is ruptured. This stage lasts about 7 hours. The residual energy release intensity decreases, the volume of the liquid steam is reduced and the boric acid solution level is set at MCP pipe height (second stage of the occurrence can be seen in Figure 7(b)).

A number of assumptions were assumed throughout the calculation, which is necessary owing to the difficulty of the processes happening in the circuit or the lack of data on the characteristics of boric acid solutions:

- During the computations, the reactor core volume and the reactor pressure chamber (RPC) volume had been allocated in the framework.

- Inacceptable conditions, the boric acid solution's thermal and physical properties - for example, density and viscosity should be assumed to be equal to the parameters of water.

- At the temperature of saturation, the core and RPC are both filled with all water.

- System pressure stays constant and is equivalent to $0.3 \mathrm{MPa}$

- All of the boric acid in the primary circuit, as well as the boric acid that enters the secondary circuit, is at saturation temperature.

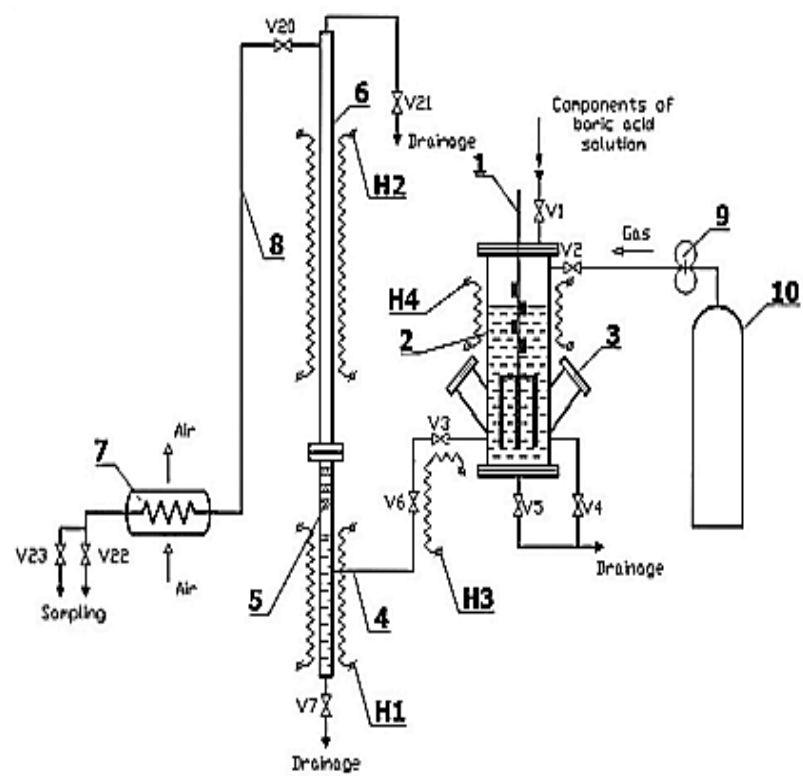

Figure 6: The test facility's process flow sheet

1) apparatus for combining; 2) tank for preparing solutions;

3) port for observation; 4) H3BO3 solution supply line; 5) separator of steam; 6) test section; 7) condenser of steam; 8) steam extraction line; 9) reducer of gas; 10) cylinder of gas;

$\mathrm{H} 1-\mathrm{H} 4$ : electrical heaters in groups

At the time of mass transfer measuring, the rated capacity of the reactor was assumed to be $3.2 \times 109 W$ (Kopytov et 
al., 2009). The parameters of the accumulators of the passive flood of HA-2 were used as the starting point for the calculations (Morozov \& Remizov, 2012b).

a)

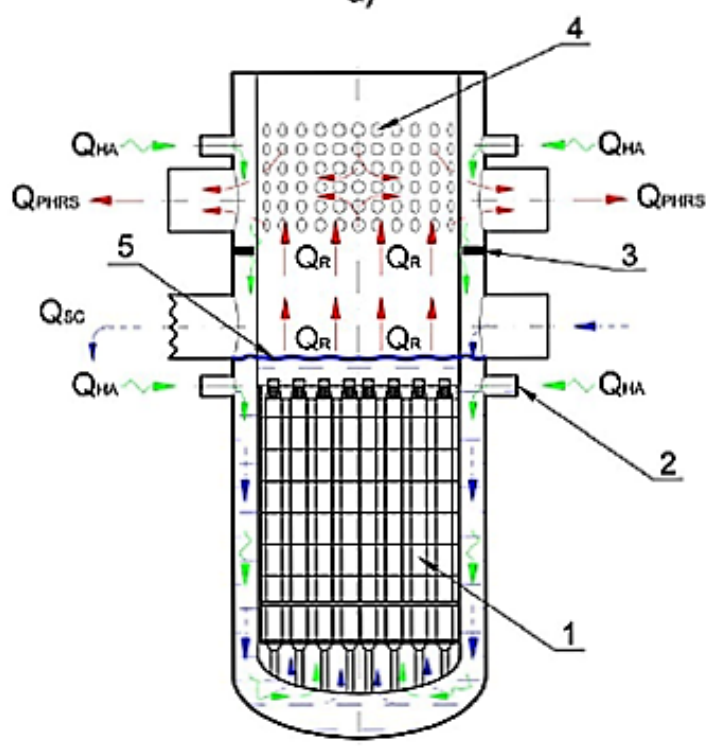

b)

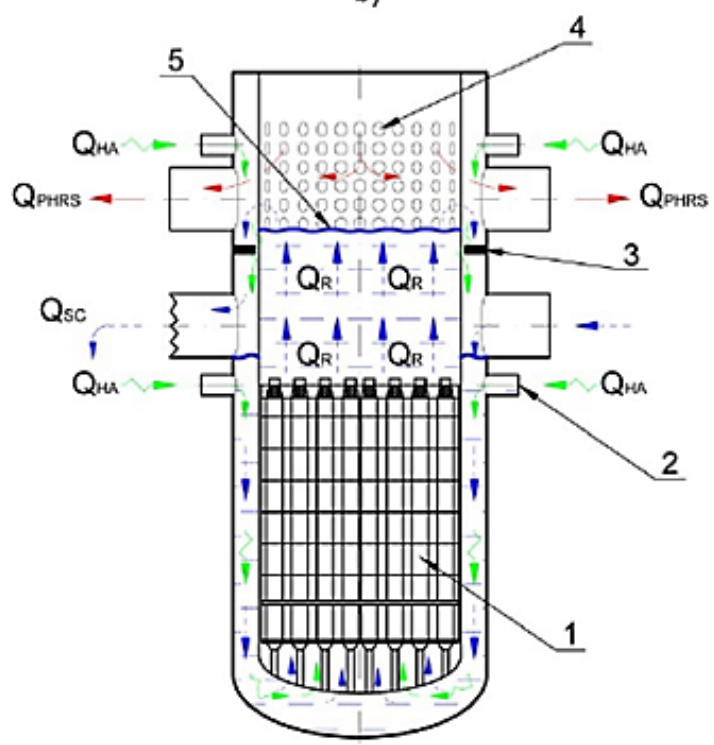

Figure 7: In the case of LOCA, a mass transfer of boric acid takes place in the VVER reactor vessel (Kopytov et al., 2009a);

a) First stage of accident; b) Second stage of accident:

1) reactor core; 2) emergency core cooling equipment nozzle;

3) separating collar; 4) reactor barrel perforations; 5) liquid content; coolant flow, steam and condensate boric acid solution intake from the HA systems; QR: denotes the amount of heat energy emitted in the reactor; QSC: the amount of energy released by steam when it passes through a leak and into the containment; The water from hydro accumulators removes energy from the core which is referred to as QHA. QPHRS: heat energy taken from the core as a result of PHRS operation.

Table 1 shows the evolution of latent heat (NRC) in the reactor core since it has been shut down (Kopytov et al., $2009 b)$. The flow rate parameters used for calculations from HA-2 passive hydraulic accumulator tanks are given in table 2 as input data.
Table 1

Residual heat in the VVER core (Schmal \& Ivanov,2015)

\begin{tabular}{cc}
\hline \hline Time (second) & Residual heat (MW) \\
\hline 100 & 0.0331 \\
1000 & 0.0206 \\
10000 & 0.0105 \\
$28.8 \cdot 10^{3}$ & 0.0077 \\
$37.8 \cdot 103$ & 0.0072 \\
$50 \cdot 10^{3}$ & 0.0067 \\
$100 \cdot 103$ & 0.0055 \\
$130 \cdot 10^{3}$ & 0.0053 \\
$500 \cdot 103$ & 0.003 \\
$147 \cdot 104$ & 0.0022 \\
$216 \cdot 104$ & 0.0018 \\
\hline \hline
\end{tabular}

Table 2

Parameters of systems of passive VVER core reservoir of hydraulic accumulation tanks (Schmal \& Ivanov, 2015)

\begin{tabular}{ccccc}
\hline \hline Parameter & $\begin{array}{c}\text { Value } \\
\text { (HA-2) }\end{array}$ & $\begin{array}{c}\text { Value } \\
\text { (HA-2) }\end{array}$ & $\begin{array}{c}\text { Value } \\
\text { (HA-2) }\end{array}$ & $\begin{array}{c}\text { Value } \\
\text { (HA-2) }\end{array}$ \\
\hline $\begin{array}{c}\text { The stage's } \\
\text { duration, } \mathrm{s}\end{array}$ & $\begin{array}{c}100 \\
5430\end{array}$ & $\begin{array}{c}5431 \\
-\end{array}$ & $\begin{array}{c}10861 \\
-\end{array}$ & $\begin{array}{c}86401 \\
-\end{array}$ \\
$\begin{array}{c}\text { Flow rate of } \\
\text { boric acid } \\
\text { solution, } \mathrm{kg} / \mathrm{s}\end{array}$ & 10.0 & 5.0 & 3.3 & 1.6 \\
\hline \hline
\end{tabular}

\section{B. Simulation by MATHCAD}

Real scenarios of emergency condition like pressure, temperature was simulated in the experimental test facility and then boric acid concentration data was obtained. The data collected from the test facility was used in several equations (for example- steam flow rate, boric acid solution flow rate etc.) in MATHCAD software. The results obtained from subsequent MATHCAD calculations were used to analyze the results of boric acid concentration graphs, flow rates, mass of boric acid etc. at emergency situation.

There is a variety of dependencies that make determining the importance of steam moisture possible. For example, for determining the water content of steam, the formula is:

$\mathrm{W}=2.75 \times 10^{8} \frac{\mathrm{N}^{2.3}}{\mathrm{Ga}^{1.1}\left[\frac{\rho^{\prime \prime}}{\rho^{\prime}-\rho^{\prime \prime}}\right]^{0.25}}$

Where $N=w_{0}^{\prime \prime 2} /(\varphi g H)$

However, this dependency is only valid for measuring steam water content when the increase in steam is equal to or less than $1 \mathrm{~m}$, which is considerably less than what is observed in case of VVER reactor. Furthermore, there are 
dependencies that enables the calculation of steam content of a steam water mixture flow $\mathrm{x}$ :

$$
\mathrm{x}=0.26\left(\frac{\mathrm{w}_{0}^{\prime \prime}}{\mathrm{g} \sqrt{\sigma / g\left(\rho^{\prime}-\rho^{\prime \prime}\right)}}\right)^{0.36}\left(\frac{\rho^{\prime \prime}}{\rho^{\prime}-\rho^{\prime \prime}}\right)^{0.12}
$$

The findings of experimental tests performed on a largescale test facility at the SSC RF-IPPE were used to determine the condensation efficiency of steam generators.

$$
\begin{aligned}
& \mathrm{N}_{\text {PHRS }}=144.8-5.885 \cdot 10^{-4} \tau+1.499 \cdot 10^{-9} \tau^{2}- \\
& 131.25+7.619 \cdot \frac{10^{4}}{\sqrt{\tau}}
\end{aligned}
$$

NPHRS is the steam generator's condensation capacity, $\mathrm{kW}$; $\mathrm{t}$ is the time, $\mathrm{s}$

The mass of evaporated water over time will be as follows:

$$
\Delta \mathrm{m}_{\mathrm{s}}\left(\mathrm{H}_{2} \mathrm{O}\right)=\frac{\mathrm{N}_{\mathrm{RC}}}{\mathrm{h}^{\prime \prime}-\mathrm{h}_{\mathrm{RPC}}} \Delta \tau
$$

Mass of the condensate formed in the steam generator due to the operation of PHRS and the mass of boric acid solution introduced into the reactor via the hydroaccumulators are:

$\Delta \mathrm{m}_{\mathrm{m}}$ (solution) $=\left(\mathrm{G}_{\mathrm{HA}}+\mathrm{G}_{\mathrm{PHRS}}\right) \Delta \tau$

The following is the mass of boric acid that entered the reactor via HAs:

$\Delta \mathrm{m}_{\mathrm{m}}\left(\mathrm{H}_{3} \mathrm{BO}_{3}\right)=\mathrm{G}_{\mathrm{HA}} \mathrm{C}_{\mathrm{HA}}\left(\mathrm{H}_{3} \mathrm{BO}_{3}\right) \Delta \tau$

The following is the quantity of boric acid solution which enters the containment:

$\Delta \mathrm{m}_{\text {out }}($ solution $)=\Delta \mathrm{m}_{\mathrm{m}}($ solution $)-\Delta \mathrm{m}_{\mathrm{s}}\left(\mathrm{H}_{2} \mathrm{O}\right)$

As a result, during the first phase of the emergency procedure, the following formula is employed to compute the boric acid concentration in the reactor core:

$\mathrm{C}_{\mathrm{i}}\left(\mathrm{H}_{3} \mathrm{BO}_{3}\right)=\frac{\left(\mathrm{m}_{\mathrm{RC}}+\mathrm{m}_{\mathrm{RPC}}\right) \mathrm{C}_{\mathrm{i}-1}+\Delta \mathrm{m}_{\mathrm{in}}\left(\mathrm{H}_{3} \mathrm{BO}_{3}\right)}{\mathrm{m}_{\mathrm{RC}}+\mathrm{m}_{\mathrm{RPC}}+\Delta \mathrm{m}_{\mathrm{in}}(\text { solution })-\Delta \mathrm{m}_{\mathrm{s}}\left(\mathrm{H}_{2} \mathrm{O}\right)}$

With time, the quantity of residual heat releases reduces along with the quantity of foamed water in the reactor.

The distance between the bottom generator of the "cold" loop of the main circuit and the top row of perforations hole in the reactor barrel is 1.845 meters and the distance between both the top of the core as well as the upper perforation holes in the core barrel is 2.77 meters. The essential steam content when the foamed water volume increases over the top row of perforations in the barrel, in the emergency situations, with a "cold" leg break is:

$$
\varphi_{\mathrm{CR}}=\frac{1.845}{2.77}=0.666
$$

The following is the formula for estimating steam content:

$\mathrm{x}=0.26\left(\frac{\mathrm{w}_{0}^{\prime \prime}}{\mathrm{g} \sqrt{\sigma / g\left(\rho^{\prime}-\rho^{\prime \prime}\right)}}\right)^{0.36}\left(\frac{\rho^{\prime \prime}}{\rho^{\prime}-\rho^{\prime \prime}}\right)^{0.12}$

Where, steam velocity:

$\mathrm{w}^{\prime \prime}=\mathrm{N}_{\mathrm{RC}} / \mathrm{r} \cdot \rho^{\prime \prime} \cdot \mathrm{F}_{\mathrm{cs}}$

Residual heat energy will heat up the boric acid solution and that will infiltrate the core from the RPC and evaporate later, in the second stage of the accident:
$\mathrm{N}_{\mathrm{RC}}=\mathrm{G}_{\mathrm{N}} \mathrm{r}+\mathrm{G}_{12}\left(\mathrm{r}+\mathrm{h}^{\prime}-\mathrm{h}_{\mathrm{RPC}}\right)$

Because of droplet entrainment mechanisms, the boric acid flow rate exiting both RPC and the core has increased $G_{R e}$ as $\mathrm{G}_{\mathrm{Re}}=\omega \mathrm{G}_{\mathrm{m}}$.

The steam-water combination departing the reactor which comprises of boric acid droplets and steam is substituted with boric acid solution via the RPC:

$\mathrm{G}_{12}=\mathrm{G}_{\mathrm{N}}+\mathrm{G}_{\mathrm{Re}}$

The following expression shows how mass of boric acid varies in the core over time:

$\Delta \mathrm{m}_{\mathrm{RC}}\left(\mathrm{H}_{3} \mathrm{BO}_{3}\right)=\left(\mathrm{G}_{12} \mathrm{C}_{\mathrm{RPC}}-\mathrm{G}_{\mathrm{Re}} \mathrm{C}_{\mathrm{RC}}\right) \Delta \tau$

As previously said, the boric acid solution through reactor pressure chamber would flow through the core at a flow rate of G12, with the excess solution being drained into the containment via the ruptured main circulation pump. The mass of the spilled solution in the containment over duration as well as the variation in mass of boric acid in the quantity of reactor pressure chamber (RPC) over the same time span may be calculated using this method:

$$
\begin{aligned}
& \mathrm{G}_{\mathrm{SC}}=\mathrm{G}_{\mathrm{HA}}+\mathrm{G}_{\mathrm{PHRS}}+\mathrm{G}_{\mathrm{Re}}-\mathrm{G}_{\mathrm{N}} \\
& \Delta \mathrm{m}_{\mathrm{RPC}}\left(\mathrm{H}_{3} \mathrm{BO}_{3}\right)=\left(\mathrm{G}_{\mathrm{HA}} \mathrm{C}_{\mathrm{HA}}+\mathrm{G}_{\mathrm{Re}} \mathrm{C}_{\mathrm{RC}}-\mathrm{G}_{12} \mathrm{C}_{\mathrm{RPC}}-\right. \\
& \left.\mathrm{G}_{\mathrm{SC}} \mathrm{C}_{\mathrm{RPC}}\right) \Delta \tau
\end{aligned}
$$

To calculate the remaining heat, we use the following formula to compute the evaporation rate:

$$
\mathrm{N}_{\mathrm{RC}}=\mathrm{G}_{\mathrm{N}}\left[\left(\mathrm{h}^{\prime \prime}-\mathrm{h}_{\mathrm{RPC}}\right)+\omega\left(\mathrm{h}^{\prime}-\mathrm{h}_{\mathrm{RPC}}\right)\right.
$$

As a result, the steam flow rate is as follows:

$\mathrm{G}_{\mathrm{N}}=\mathrm{N}_{\mathrm{RC}} /\left(\mathrm{h}^{\prime \prime}-\mathrm{h}_{\mathrm{RPC}}\right)+\omega\left(\mathrm{h}^{\prime}-\mathrm{h}_{\mathrm{RPC}}\right)$

The following expression shows the change in boric acid content in reactor core throughout time:

$\Delta \mathrm{C}_{\mathrm{RC}}\left(\left(\mathrm{H}_{3} \mathrm{BO}_{3}\right)=\Delta \mathrm{m}_{\mathrm{RC}}\left(\frac{\left(\mathrm{H}_{3} \mathrm{BO}_{3}\right)}{\mathrm{m}_{\mathrm{RC}}}\right)\right.$

\section{RESULTS AND DISCUSSION}

Changes in concentration of boric acid in the reactor core and reactor pressure chamber are calculated using the equations and assumptions listed above. The concentration of boric acid in the tanks of the passive core re-flooding systems is currently $16 \mathrm{~g} / \mathrm{kg} \mathrm{H} 2 \mathrm{O}$ according to NPP operating legislation (Kalyakin et al., 2003). Variants of decreasing $\mathrm{H}_{3} \mathrm{BO}_{3}$ concentration in $\mathrm{HA}-2$ method to $16 \mathrm{~g} / \mathrm{kg} \mathrm{H}_{2} \mathrm{O}$ are included in this measurement. From the experiment, we got the data of boric acid concentration at specific parameters - for example, at a specific pressure and temperature. Then this data obtained from the experiment has been used in calculations to analyse how the boric acid concentration changes over time and helps us to investigate whether the boric acid reaches the point of crystallization within 24 hours of a large loss of coolant accident. So, the experiment gives us the starting/input data that is used for numerical analysis in MATHCAD. So, the primary data is given by the experiment and the final result comes from the numerical analysis.

Figure 8(a) and 8(b) shows the results of the numerical analysis. Figure 8(a) shows the concentration curve of 
boric acid in the event of boric acid $\left(\mathrm{H}_{3} \mathrm{BO}_{3}\right)$ solubility with steam and 8(b) indicates the concentration curve of boric acid in the event of boric acid $\left(\mathrm{H}_{3} \mathrm{BO}_{3}\right)$ solubility without steam. The amount of boric acid that accumulates in the reactor core after an emergency process can be seen. It is important to note that the boric acid concentration in the reactor core is $0.311 \mathrm{~kg} / \mathrm{kg}$ after 24 hours of emergency phase and does not exceed the solubility maximum. The solubility limit (C Limit) is about $0.415 \mathrm{~kg} / \mathrm{kg}$ at water saturation temperature. The value of boric acid drop entrainment from the core was assumed to be 0.2 percent during this measurement. Figure 8(a) was calculated using the normal value for steam moisture at the steam generator's output. $\tau_{\varphi . c r}$, the green line divides the emergency period during accident. In Figure 8(a), the blue line indicates the boric acid concentration in the accidental period. We found that at the primary stage of emergency process, the boric acid concentration is more or less constant.

After the first stage of hydro accumulators operate, second stage hydro accumulators start to operate and we see that during the time period of second stage hydro accumulator operation, the concentration of boric acid gradually increase. From numerical analysis in MathCAD, it is found that the final concentration of boric acid with the steam solubility is about $0.153 \mathrm{~kg} / \mathrm{kg}$. But it is much below the limiting boric acid concentration (C Limit). And the yellow line indicates the limiting concentration $(0.415 \mathrm{~kg} / \mathrm{kg})$ of boric acid.

So, in Figure 8(b) we see that boric acid concentration curve is almost similar with the previous result. This graph indicates the boric acid concentration (brown line) without steam solubility in accordance with time range of whole emergency process. As we can see in Figure 8(b), the boric acid's concentration of core is more or less constant during the initial stage of emergency process. Then with the operation of hydro accumulator second stage the boric acid's concentration curve goes slightly higher. By calculation, we found that after 24 hours of operation of hydro accumulator second stage, the concentration amount (without solubility of steam) is found $0.158 \mathrm{~kg} / \mathrm{kg}$. But most importantly, it is also significantly below the limiting concentration of boric acid (blue line).

The concentration of boric acid in reactor pressure chamber (RPC) was fluctuating a little bit during initial emergency process and after the second stage hydro accumulator operation, the concentration graph of boric acid decreases sharply and become constant. Because there is a flow rate of condensate from steam generator with zero boric acid solution and it is mixing with boric acid solution from the HA-2 system, so, the final concentration is low. And another reason is that, there is no boiling condition in RPC, the concentration of boric acid has not increased like in the core. But importantly, it is also substantially lower than the boric acid limiting concentration. (blue line). So, for VVER-1200, the hydro-accumulator 2nd stage operation during an emergency process prevents the accumulation of boric acid in the core as well as in the reactor pressure chamber (RPC). These states are proved by this calculation.

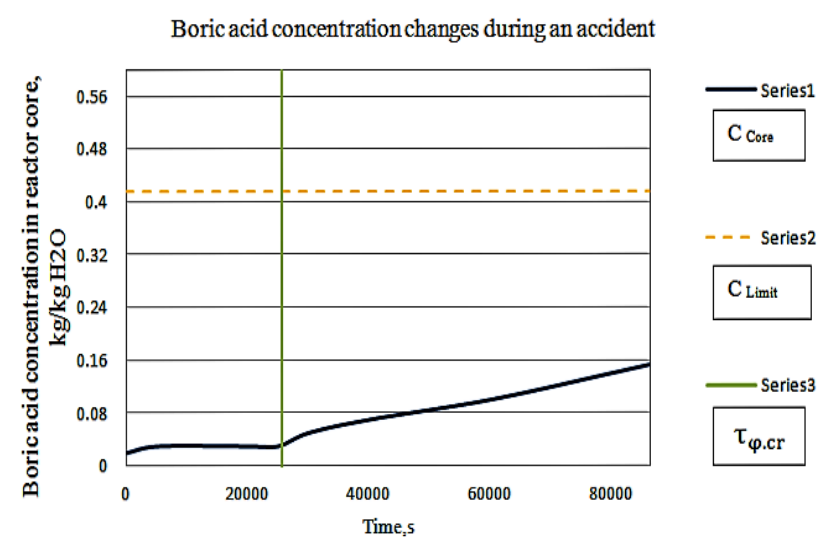

(a)

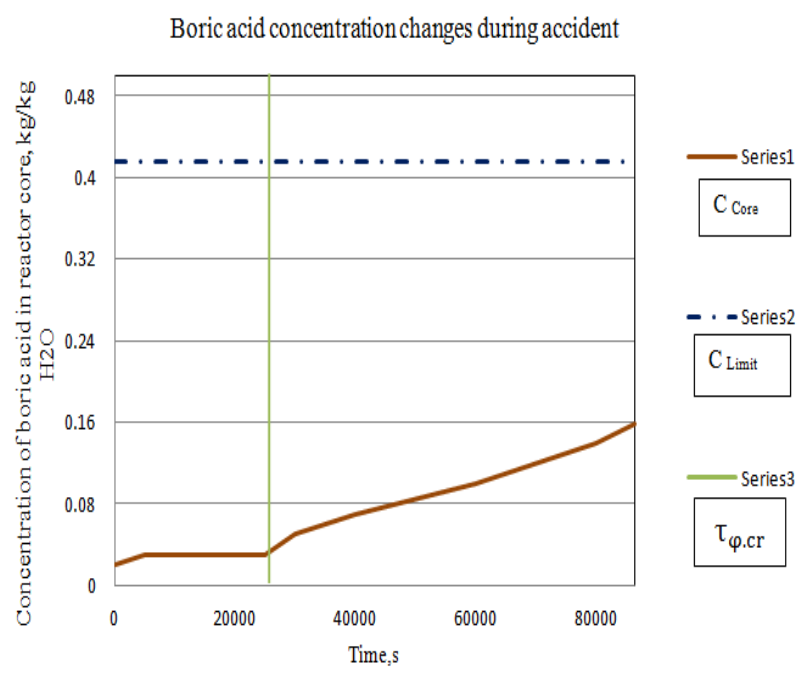

(b)

Figure 8: (a) The concentration of boric acid in the reactor core changes (with solubility of steam), (b) The concentration of boric acid in the reactor core changes (without solubility of steam)

As previously said, deposits of boric acid in the core have a direct effect on heat recovery during the emergency procedure. So, the mass of the boric acid deposit was calculated as well. The following formula was used to quantify the deposit mass, $\mathrm{m}_{\mathrm{dep}}\left(\mathrm{H}_{3} \mathrm{BO}_{3}\right)$ :

$\mathrm{m}_{\mathrm{dep}}\left(\mathrm{H}_{3} \mathrm{BO}_{3}\right)=\mathrm{m}_{\mathrm{RC}}\left(\mathrm{C}_{\mathrm{RC}}\left(\mathrm{H}_{3} \mathrm{BO}_{3}\right)-\mathrm{C}_{\text {lim }}\right.$

During the measurement analysis, it was discovered that the available dependencies for estimating steam moisture and steam quality of the medium at the VVER core's outlet in the event of an emergency are currently unknown. These variables are critical for understanding boric acid mass transport processes. Experiments on the mass transfer processes of $\mathrm{H} 3 \mathrm{BO} 3$ should be carried out at parameters that are equivalent to the emergency mode parameters of VVER reactors to remove current uncertainties. By calculation analysis it is seemed that flow rates of hydroaccumulators and PHRS (passive heat removal systems) decreases with the period of time. The HA-2 flow rates are given in Table 2 previously. The flow rate of HA-2 decrease at a constant rate and it is very effective to cool down the reactor core and reactor pressure chamber as 
well. And the passive cooling through steam generator (PHRS) flow rate is also decrease with the period of time as shown in Figure 9.

We see that the GPHRS is decreasing in the graph continuously because of low steam production in the reactor core with the time. The flow rate of PHRS becomes $8.2 \mathrm{~kg} / \mathrm{s}$ after whole emergency process and it prevents the crystallization of boric acid in the reactor core and containment volume (CV). So, these following graphs describe enough to study the flow rates of hydroaccumulators 2nd stage and passive heat removal systems through steam generators. Figure 6 shows the change of flow rates of PHRS and hydro-accumulator 2nd stage in the core throughout the entire emergency situation. During calculations it is seemed that there is no precipitation of boric acid occurs. So, mprecipitation $=0$ during 24 hours after an accident so there is no precipitation line in the following Figure. So, the deposit mass of boric acid in the reactor core is almost zero after initial emergency process. The blue line indicates the flow rate of $H A-2$ which gradually decreases stage by stage. In the final stage the flow rate is become constant which is $1.6 \mathrm{~kg} / \mathrm{s}$.

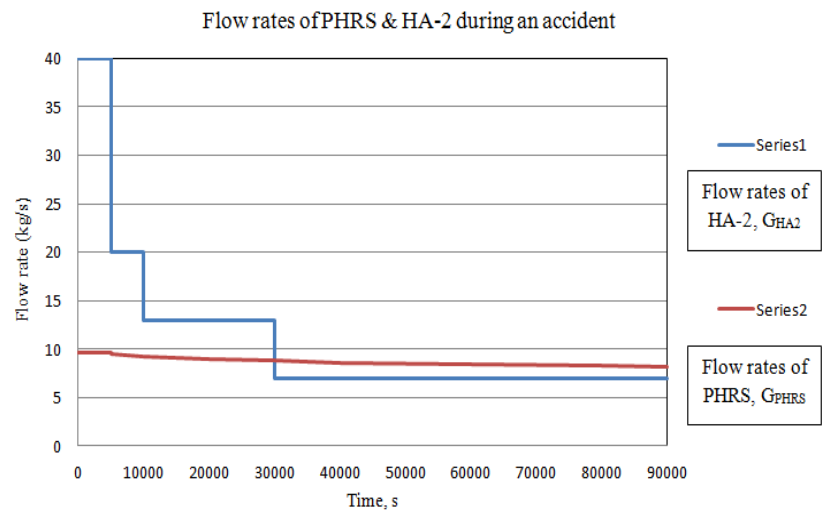

Figure 9: Change of flow rates of PHRS and hydroaccumulator 2 nd during the whole emergency process

In Figure 10, the flow rate of boric acid due to droplet entrainment is observed (green line), after being critical the flow rate is decreasing according to the time. In the initial stage of emergency process, the values of droplet entrainment are impossible to be measured because the water level is too low inside the core.

And boric acid flow rate from RPC to core is constant (red line) during the emergency process. During calculation, it is found that a significant amount of boric acid escapes from reactor core as well as containment volume with steam and droplet entrainment process. Because, we know that during emergency, reactor core is in boiling state, so, when boric acid solution enters into the core, maximum solution turns into vapor which contains boric acid. Then the steam with boric acid comes out from reactor core to containment volume. As we know that droplet entrainment is an entrapment of substances, so with liquid, boric acid is entrapped and comes out through the rupture of main circulation pipelines. It is very helpful to prevent the boric acid accumulation or deposit mass of boric acid inside the core and containment volume during the whole emergency process. After 24 hours of initial emergency conditions it is found that no precipitation of boric acid is found inside area or active area of the reactor.

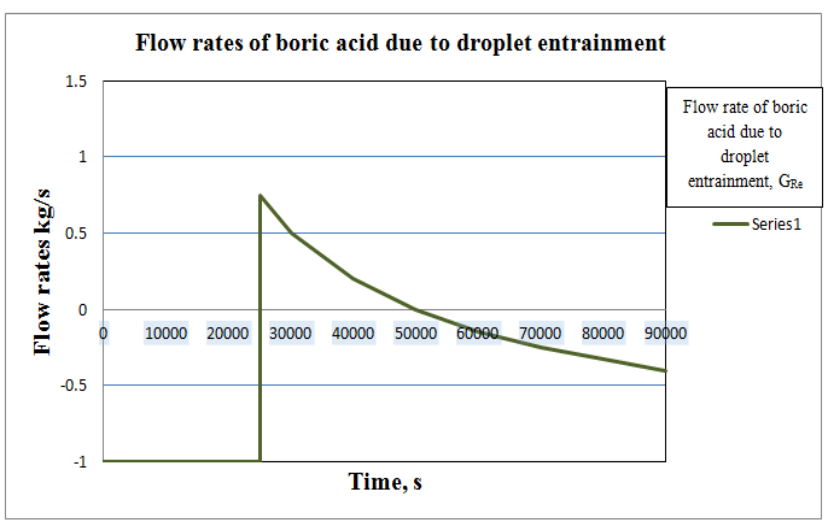

Figure 10: Change of boric acid flow rate in the core because of droplet entrainment during the whole emergency process

\section{CONCLUSION}

The determination of boric acid mass transfer processes plays a significantly role in the analysis of emergency mode operations in modern VVER reactors. In the VVER1200 reactor core, the computed estimation revealed a considerable amount of concentration of boric acid 24 hours after the incident began. This process may not result in crystallization on the surface of the fuel rods and do not hamper in heat removal through the core. It should be noted that the estimation was based on a set of conservative values that did not take into consideration the removal of solution of boric acid from the core due to the capacity of steam to dissolve it. During the calculation study, it was discovered that the available dependencies for estimating steam moisture as well as steam content of the mediums at the VVER core's exit in the event of an emergency are currently questionable. Because, at such emergency situation, the steam moisture and steam content parameters vary which leads to an uncertainty in variable dependencies. These variables are critical for understanding the boric acid mass transfer mechanisms. Experiments on the mass transfer processes of H3BO3 should be carried out at parameters that are equivalent to the emergency mode parameters of VVER reactors to remove current uncertainties.

\section{NOMENCLATURES}

G

Factor of gravity

$\sigma \quad$ Liquid tension

$h^{\prime \prime} \quad$ Steam enthalpy at saturation temperature $(\mathrm{kJ} / \mathrm{kg})$

$h_{R P C} \quad$ Boric acid solution enthalpy in RPC $(\mathrm{kJ} / \mathrm{kg})$

$G_{H A} \quad$ Boric acid solution flow rate from $\mathrm{HA}(\mathrm{kg} / \mathrm{s})$

$G_{P H R S} \quad$ The flow rate of condensate in SG $(\mathrm{kg} / \mathrm{s})$

$m_{R C} \quad$ Mass of boric acid solution in core $(\mathrm{kg})$

$m_{R P C} \quad$ The amount of boric acid solution in RPC (kg)

$G_{N} \quad$ Steam output rate (kg/s)

$G_{12} \quad$ Rate of flow of a boric acid solution to the core via RPC (kg/s)

$r \quad$ Evaporation specific heat $(\mathrm{kJ} / \mathrm{kg})$ 


$\begin{array}{ll}h^{\prime} & \begin{array}{l}\text { The enthalpy of water is at saturation } \\ \text { temperature }(\mathrm{kJ} / \mathrm{kg})\end{array} \\ h_{R P C} & \begin{array}{l}\text { Boric acid solution enthalpy in RPC }(\mathrm{kJ} / \mathrm{kg}) \\ C_{R P C}\end{array} \\ \begin{array}{l}\text { Boric acid solution concentration in RPC } \\ (\mathrm{kg} / \mathrm{kg})\end{array} \\ C_{R C} & \begin{array}{l}\text { In the core of the reactor, the concentration of } \\ \text { boric acid solution }(\mathrm{kg} / \mathrm{kg})\end{array} \\ G_{m} & \text { Flow rate of steam-water combination }(\mathrm{kg} / \mathrm{s})\end{array}$

\section{RECOMMENDATIONS}

Unfortunately, this work was limited to the calculation in the time range of 24 hours of emergency condition. It would be great to do the application of this calculation methodology as well as the results obtained for the case with operation of VVER third-stage hydraulic accumulators (up to 72 hours).

\section{ACKNOWLEDGEMENTS}

This work was supported by the Department of Nuclear Physics and Engineering, National Research Nuclear University (MEPhI), Moscow, Russia.

\section{REFERENCES}

Cohen, P. (1973). Water technology of power reactors. Springer Publishing.

Hassan, A. Y., Osturk, S., \& Lee, S. (2015). Progress in Nuclear Engineering. Progress in Nuclear Engineering, 85, 239-253.

Hewitt, G. F., \& Hall-Taylor, N. S. (1970). Annular Two-phase Flow (136-148). Pergamon Press, N. Y.

Ishii, M., \& Grolmes, M. A. (1975). AIChE Journal. Inception Criteria for Droplet Entrainment in Two-Phase Concurrent Film Flow, 21(2), 308-318.

Kalyakin, S. G., Remizov, O. V., Morozov, A. V., YU.S., Y. U. R'. E. V., \& YU.V., K. L. I. M. A. N. O. V. A. (2003). Proceedings of Graduate Schools. Nuclear Power Engineering. Substantiation of Design Functions of the Passive Flood System HA-2 for Improved NPP Project with VVER Reactor, 2, 94-101.

Kalyakin, S. G., Sorokin, A. P., Pivovarov, V. A., Pomet'ko, R. S., Selivanov, Y. U. F., Morozov, A. V., \& Remizov, O. V. (2014a). Atomic energy. Experimental Studies of the Thermo Physical Processes in Justification of the Safety of the New Generation of VVER, 114(4), 241-246.

Kalyakin, S. G., Sorokin, A. P., Pivovarov, V. A., Pomet'ko, R. S., Selivanov, Y. U., Morozov, A. V., \& Remizov, O. V. (2014b). Atomnaya energiya. Experimental Research of Thermal Physical Processes for the Safety Substantiation of New Generation VVER, 116(4), 241-246.
Kopytov, I. I., Kalyakin, S. G., Berkovich, V. M., Morozov, A. V., \& Remizov, O. V. (2009a). Experimental investigation of non-condensable gases effect on Novovoronezh NPP-2 steam generator condensation power under the condition of passive safety systems operation. Proceedings of theXYII-th International Conference on Nuclear Engineering, ICONE17. International Conference on Nuclear Engineering, ICONE17, Brussels.

Kopytov, I. I., Kalyakin, S. G., Berkovich, V. M., Morozov, A. V., \& Remizov, O. V. (2009b). Proc. 17 Int.Conf. on Nuclear Engineering. 735-743.

Morozov, A., \& Sakhipgareev, A. (2017). Experimental estimation of the effect of contact condensation of steamgas mixture on VVER passive safety systems operation. Nuclear Energy and Technology, 3(2), 98-104. https://doi.org/10.1016/j.nucet.2017.05.002

Morozov, A. V., \& Remizov, O. V. (2012a). Teploenergetika. Experimental Justification for Design Functions of Additional Passive Re Flooding Systems of the Reactor VVER Core., 5, 22-27.

Morozov, A. V., \& Remizov, O. V. (2012b). Thermal Engineering. Experimental Substantiation of Design Functions of the VVER Auxiliary System of Passive Core Reflooding, 5, 22-27.

Morozov, A. V., \& Remizov, O. V. (2012c). Thermal Engineering. Experimental Study of VVER Steam Generator Model Operation in Condensation Mode, 5, 16-21.

Morozov, A. V., \& Remizov, O. V. (2012d). Thermal Eng: Vol. 59 (365-370). Springer Publishing. https://doi.org/10.1134/S0040601517050044

Morozov, A. V., Remizov, O. V., \& Tsyganok, A. A. (2009). Proceedings of Graduate Schools. Nuclear Power Engineering. Experimental Study of Non-Equilibrium Thermal-Hydraulic Processes in a Passive VVER Core Reflooding System, 4, 115-123.

Newitt, D. M., Dombrowski, N., \& Knelman, F. H. (1954). Trans. Inst. Chem. Eng. "Liquid Entrainment: I, The Mechanism of Drop Formation from Gas or Vapor Bubbles, “, 32, 244.

Schmal, I. I., \& Ivanov, M. A. (2015a). Boric acid mass transfer processes in accidental conditions. Proc. of the 9th Int. Scientific and Technical Conference «Safety Assurance of VVER NPP». Podolsk, JSC EDO «Gidropress». Published.

Schmal, I. I., \& Ivanov, M. A. (2015b). Boric acid mass transfer processes in accidental conditions. 25-29.

Schmal, I. I., \& Ivanov, M. A. (2015c). Safety assurance of NPPs with WWER. 25-29.

Vallée, C., Höhne, T., \& S. (2008). Two-phase flow phenomena, Experimental Investigation and CFD Simulation of Horizontal Stratified Two-Phase Flow Phenomena, 238(3), 637-646. 